\title{
The weekend effect: does hospital mortality differ by day of the week? A systematic review and meta-analysis
}

\author{
Kate Honeyford $^{1 *}$ (D), Elizabeth Cecil ${ }^{1}$, Michelle Lo ${ }^{2}$, Alex Bottle ${ }^{1}$ and Paul Aylin ${ }^{1}$
}

\begin{abstract}
Background: The concept of a weekend effect, poorer outcomes for patients admitted to hospitals at the weekend is not new, but is the focus of debate in England. Many studies have been published which consider outcomes for patients on admitted at the weekend. This systematic review and meta-analysis aims to estimate the effect of weekend admission on mortality in UK hospitals.

Methods: This is a systematic review and meta-analysis of published studies on the weekend effect in UK hospitals. We used EMBASE, MEDLINE, HMIC, Cochrane, Web of Science and Scopus to search for relevant papers. We included systematic reviews, randomised controlled trials and observational studies) on patients admitted to hospital in the UK and published after 2001. Our outcome was death; studies reporting mortality were included. Reviewers identified studies, extracted data and assessed the quality of the evidence, independently and in duplicate. Discrepancy in assessment was considered by a third reviewer. All meta-analyses were performed using a random-effects metaregression to incorporate the heterogeneity into the weighting.
\end{abstract}

Results: Forty five articles were included in the qualitative synthesis. 53\% of the articles concluded that outcomes for patients either undergoing surgery or admitted at the weekend were worse. We included 39 in the meta-analysis which contributed 57 separate analyses. We found an effect of 1.07 [odds ratio (OR)] (95\%Cl:1.03-1.12), suggesting that patients admitted at the weekend had higher odds of mortality than those admitted during the week. Sub-group analyses suggest that the weekend effect remained when measures of case mix severity were included in the models (OR:1.06 95\%Cl:1.02-1.10), but that the weekend effect was not significant when clinical registry data was used (OR:1.03 95\%Cl: 0.98-1.09). Heterogeneity was high, which may affect generalisability.

Conclusions: Despite high levels of heterogeneity, we found evidence of a weekend effect in the UK, even after accounting for severity of disease. Further work is required to examine other potential explanations for the "weekend effect" such as staffing levels and other organisational factors.

Trial registration: PROSPERO International Prospective Register of Systematic Reviews -registration number: CRD42016041225.

Keywords: Quality of care, Hospital, Weekend effect, Mortality

\footnotetext{
* Correspondence: k.honeyford@imperial.ac.uk

Kate Honeyford and Elizabeth Cecil are joint first authors.

${ }^{1}$ Department of Primary Care and Public Health, Dr Foster Unit at Imperial

College, 3 Dorset Rise, London EC4Y 8EN, UK

Full list of author information is available at the end of the article
}

(c) The Author(s). 2018 Open Access This article is distributed under the terms of the Creative Commons Attribution 4.0 International License (http://creativecommons.org/licenses/by/4.0/), which permits unrestricted use, distribution, and reproduction in any medium, provided you give appropriate credit to the original author(s) and the source, provide a link to the Creative Commons license, and indicate if changes were made. The Creative Commons Public Domain Dedication waiver (http://creativecommons.org/publicdomain/zero/1.0/) applies to the data made available in this article, unless otherwise stated. 


\section{Background}

The concept of a "weekend effect" is not new. From as early as the 1970s, researchers have reported poorer outcomes for patients admitted or treated at the weekends across a variety of medical settings, diagnoses, procedures and countries [1-4]. However, recently the "weekend effect" has prompted controversy, particularly in the UK (United Kingdom), as demonstrated by the increasing use of the common prefix in research papers and newspaper articles: 'so-called' [5, 6]. This controversy, particularly in the UK, appears to have been inflamed by an announcement on 13th October 2015 by the Secretary of State for Health, claiming that avoidable deaths occurred at weekends because there was not a full seven-day NHS (National Health Service) service; specifically he claimed that "there are 11,000 excess deaths as a result of inadequate cover at weekends" [7]. The BMJ subsequently pointed out that the research he cited to support his statement did not attribute the deaths to poor staffing and did not claim that the deaths were necessarily avoidable. The Secretary of State's claim soon became part of an ongoing industrial dispute between junior doctors and the government about the introduction of a new contract. The dispute originally began in October 2013 and led to strike ballots in November 2015 [8]. The weekend effect became part of a public debate between junior doctor campaigners, academics and the Department of Health; research articles gained increased exposure and became a focus for journalists, health bloggers and clinicians.

Amidst the controversy a number of explanations have been put forward for the weekend effect. The first is that patients admitted at the weekend are 'sicker' and outcomes can therefore be expected to be worse. A second is that staffing levels are lower at weekends and this causes delays in diagnostics and procedures. A third explanation is that there is no weekend effect, and that outcomes for patients admitted at weekends are not worse and that studies who report this are actually seeing a statistical artefact. A number of systematic reviews have been published which might have assisted in settling the controversy. In 2014, Sorita et al. carried out two meta-analyses reporting the 'off-hours effect' for acute myocardial infarction and acute ischaemic stroke $[9,10]$. Significant off-hours effects were found for both diagnoses. In a meta-analysis Zhou et al. [11] found an 'off-hours effect' for 20 out of 28 diseases, including several malignancies, cardiovascular disease and stroke. More recently, Pauls et al. [12] have published a meta-analysis of the "weekend effect", and attempted to determine whether staffing is associated with the weekend effect. They found that patients admitted on the weekends had a significantly higher overall mortality. When analysing a subset of papers that included information on staffing, they found a significantly higher mortality for weekend patients, associated with decreased staffing levels, and no significant difference in mortality for weekend patients when staffing was similar to that for the weekdays. Hoshijima et al. [13] analysed the 88 international studies and found a $12 \%$ increased odds for short term mortality for patients admitted at the weekend and found a consistent effect across all continents. In line with Zhou et al. [11] they found a weekend effect in specific disease groups and suggest that this was related to these diseases needing urgent diagnosis and treatment. However, some disease groups had small numbers of studies (one or two). These systematic reviews were international in scope, which gives an important global picture of health care. Given the heterogeneity of healthcare systems internationally, and the UK centric focus of some controversy around the evidence for the weekend effect, we have systematically reviewed the evidence for the weekend effect on mortality within the public healthcare system (the National Health Service) solely in the UK. We also hypothesised that the date of publication (before and after the announcement by the Secretary of State's claims surrounding the weekend effect), sample size, the data source and the extent of severity adjustment might impact upon the strength of the association between weekend admissions and mortality.

Our systematic review includes studies on patients admitted to hospital in the UK, either as elective or emergency patients, and published after 2001. In this review we confine the outcome to death defined by day of the week or combined as weekend/weekday.

The many reasons given to explain the weekend effect and explain different results led to us developing key questions to be investigated using sub-group analyses.

A) Are studies which find no weekend effect small and under-powered to detect a weekend effect?

B) Is the weekend effect only a result of more severe patients being admitted at the weekend?

a. Is a weekend effect found when clinical sets only are analysed, in comparison to administrative datasets which generally have more limited information on illness severity?

b. Does the weekend effect remain when studies which have highlighted severity measures in their analysis are included as a sub-group?

In addition, we hypothesised that studies published after the controversial statement by the Minister of Health that excess deaths were directly attributable to a weekend effect might bias researchers' interpretations of results because of the perceived views of policy makers and appropriation of research results in support of an ongoing industrial dispute. 


\section{Methods}

\section{Search methods for identification of studies}

The review protocol has been registered in the PROSPERO International Prospective Register of Systematic Reviews (registration number: CRD42016041225). The protocol considers both processes and outcomes: here we focus on outcomes. We hope to publish further work on processes in the future. The review has been written according to the Preferred Reporting Items for Systematic Reviews and Meta-Analyses (PRISMA) statement.

A primary search was carried out in July 2016. Studies were identified through 6 databases - EMBASE, MEDLINE, HMIC, Cochrane, Web of Science and Scopus. The full search strategy for each database is shown in Additional file 1. Further studies were identified from investigating study references, and a final search of MEDLINE was carried out in July 2017.

\section{Assessment of literature for inclusion}

Two reviewers independently assessed the literature for inclusion in both the primary (A and B) and final ( $\mathrm{C}$ and B) search.

\section{Inclusion criteria}

For our systematic review, we included published systematic reviews, randomised controlled trials and observational studies. We excluded studies published prior to 2002 to reflect a period of relative stability in the provision of health care in the UK. We included studies on patients admitted to hospital in the UK regardless of age, admission type (elective or emergency), medical specialty or diagnosis at admission. Our comparison was weekend vs weekday and we included all studies that defined outcomes by day of the week or combined as weekend/weekday. Our outcome was death and only studies reporting mortality (in-hospital or all mortality over any time period up to one year) were included.

\section{Data extraction and quality assessment}

Data was extracted by two reviewers: (A and B in the first search; $C$ and $B$ in second). Extracted data included date of study publication (where possible this was supplemented by date of submission), data source (clinical registry or administrative), comparison type (day of the week, or weekend vs weekday), day of baseline, admission type and adjustment approach. In addition, extracted data included sample size and estimate type (relative risk, odds ratio and hazard ratio).

This review used adapted CASP tools for evidence appraisal and bias assessment. [Casp2013] Utilising a series of questions, the CASP checklist assessed the study validity, application to research question, result significance and generalisability. The assessment of the bias was carried out separately by two reviewers (A and C) any discrepancy in assessment was considered by a third reviewer (B) to gain a consensus. Eight aspects of quality were reviewed: these are summarised in Table 1 . We considered whether patients had been excluded without a clear rationale and whether the study described confounders and took these into account. Studies were considered generalizable if they covered a wider geographical area than a single hospital trust. The Kappa statistic was used to determine the inter-rater reliability prior to the third reviewer resolving discrepancies in assessment.

\section{Data synthesis and analysis}

Initially we summarised studies based on the extraction variables (e.g. publication and submission date, data source, and severity adjustment). In addition, all papers were read by two reviewers to determine the overall conclusion of the paper. The overall conclusion of the study was compared with results presented in the main findings of the paper. For each study, we determined whether a measure of severity was included in the case-mix adjustment. In order for an adjustment measure to be defined as 'severity' it had to be a clinical factor specific to the disease of focus in the study, or, if all cause, specific to the diagnosis of the individual patient. We did not consider comorbidities or medical history to be measures of severity.

In order to carry out the meta-analysis we included only studies with underlying data and not just effect estimates. We used the authors' definition of weekend and mortality as the main outcome. When papers reported mortality over different time periods we selected 30-day as the main one. Adjusted outcomes were used in preference to unadjusted outcomes when both were given. In cases where there were multiple analyses for different diagnoses and a combined analysis, the estimates from the combined analysis (based on all diagnoses) were taken; when there was no combined analysis, the estimates for the individual diagnoses were taken. Studies reporting odds ratios and their confidence interval were included in the meta-analysis. Risk ratios were converted to odds ratios in studies where provided data allowed. Analyses estimating hazard ratios were not included in the main meta-analysis, but analysed separately.

Table 1 Aspects of quality reviewed

\footnotetext{
1. Did the review answer a clearly focused question?

2. Was the cohort recruited in an acceptable way?

3. Was the exposure accurately measured to reduce bias?

4. Has the study identified any confounding factors?

5. Has the study taken into account all of the confounding factors in the analysis

6. Was the outcome accurately measured to minimise bias?

7. How precise are the results?

8. How generalizable are the results?
} 
To estimate heterogeneity we used the Cochran Q score (reported as $\mathrm{I}^{2}$ ). All meta-analyses were performed using a random-effects meta-regression to incorporate the heterogeneity into the weighting, which includes a measure of the study size.

We carried out subgroup analyses to investigate the effect of study factors to the overall effect estimate. We carried out four subgroup analyses: a) studies published before and after 13th October 2015 (the date of the Ministerial statement on the weekend effect); b) data sourced from clinical registries compared with data sourced from administrative sources; c) study sample size - divided into four categories determined a priori; and d) inclusion of severity measure in the adjustment approach compared with no inclusion of severity of measure.

\section{Patient involvement}

We involved no patients in the development of the research question or in the selection of study design and outcome measures. No patients were involved in the conduct of the study. We do not plan to disseminate the results to study participants.

\section{Results}

\section{Studies included}

We screened the title and abstract of 1555 articles and 96 were assessed for eligibility. 47 full-text articles initially met our inclusion criteria. All articles were observational studies. Two of these articles were later excluded from both the qualitative synthesis and quantitative analysis. Although McShane et al. [14] met the inclusion criteria, when we attempted to include it in the quantitative synthesis it was determined that it was not possible to separate the results for the UK and Ireland. In addition, Mohammed et al. [15] [retracted 2017] met the inclusion criteria but was later retracted. 45 articles were included in the qualitative synthesis and 39 in the quantitative analysis (see Fig. 1). Articles were excluded from the quantitative analysis when there was insufficient information reported, for example when the article reported statistics without information on the variability of the estimate. A summary of study characteristics and assessment of bias is included in the Additional file 1.

\section{Quality of studies}

In general the quality of the papers was deemed to be good. They used validated data sources including clinical audits and administrative data sets and used recognised statistical methods to answer focussed questions. The majority of the studies adjusted for confounders within the scope of the data. The main bias identified in review is that clinical audits, by their nature, are quite small and this means confidence intervals are quite large affecting the precision of results and, although not evidence by our interpretation of the CASP question, different studies adjusted for different confounders, and this affects the robustness of the meta-analysis. Studies which focussed on one hospital trust or site were considered to have limited generalisability and this was another source of bias.

Agreement between 1st and 2nd reviewer ranged between 55 and $98 \%$ median $81 \%$. All disputes were settled by reviewer 3 . However, because of the large number of studies determined as good there was little variability resulting in low kappa statistics [range 0-0.66]. A lack of agreement centred on reviewers' specific interpretation of certain CASP questions.

\section{Outcome}

Although we extracted only papers that considered the outcome 'death', there was a wide variety in the specific way in which mortality was defined. 21 of the studies (47\%) focussed on deaths in hospital, whereas 19 (42\%) tracked patients after discharge and death in and out of hospital was the outcome. For five studies we were unable to determine whether patients were tracked after discharge. The most common time frame for tracking patients after death was 30 days, although this varied from one week to one year. The weekend was defined as midnight on Friday to midnight on Sunday in 21 studies, with the majority of other studies using the phrase Saturday and Sunday with no further detail given. One study used 16:00 on Friday to 16:00 on Sunday; [16] Saturday 07:00 to Monday 07:00 and Saturday 08:00 to Monday 08:00 were used by [17] et al. and [18] et al. respectively.

\section{Qualitative synthesis Year of publication}

There has been an increase in publication rate since 2002, with a steep increase in 2015 and 2016. We were particularly interested in the impact of the Secretary of State for Health's claim of 11,000 excess deaths based on the Freemantle paper [19]. Therefore we also looked at the precise date of publication and the date of submission. Of the nine papers published in 2015, three papers were published after Oct 13 2015, and two of these were originally submitted before this date. It was not possible to determine the submission date of the third. Of the papers published in 2016 three papers were submitted before the date Secretary of State for Health's statement. For four papers it was not possible to determine the date of submission.

\section{Data sources}

Only 11 studies had sample sizes of 100,000 or more; 10 studies had sample sizes of less than 1000. 28 studies analysed administrative data, NHS Hospital Episode Statistics or equivalent data sets from Scotland and Wales. Four studies used national stoke audit data, five other national audits were used and 10 local audits, which 


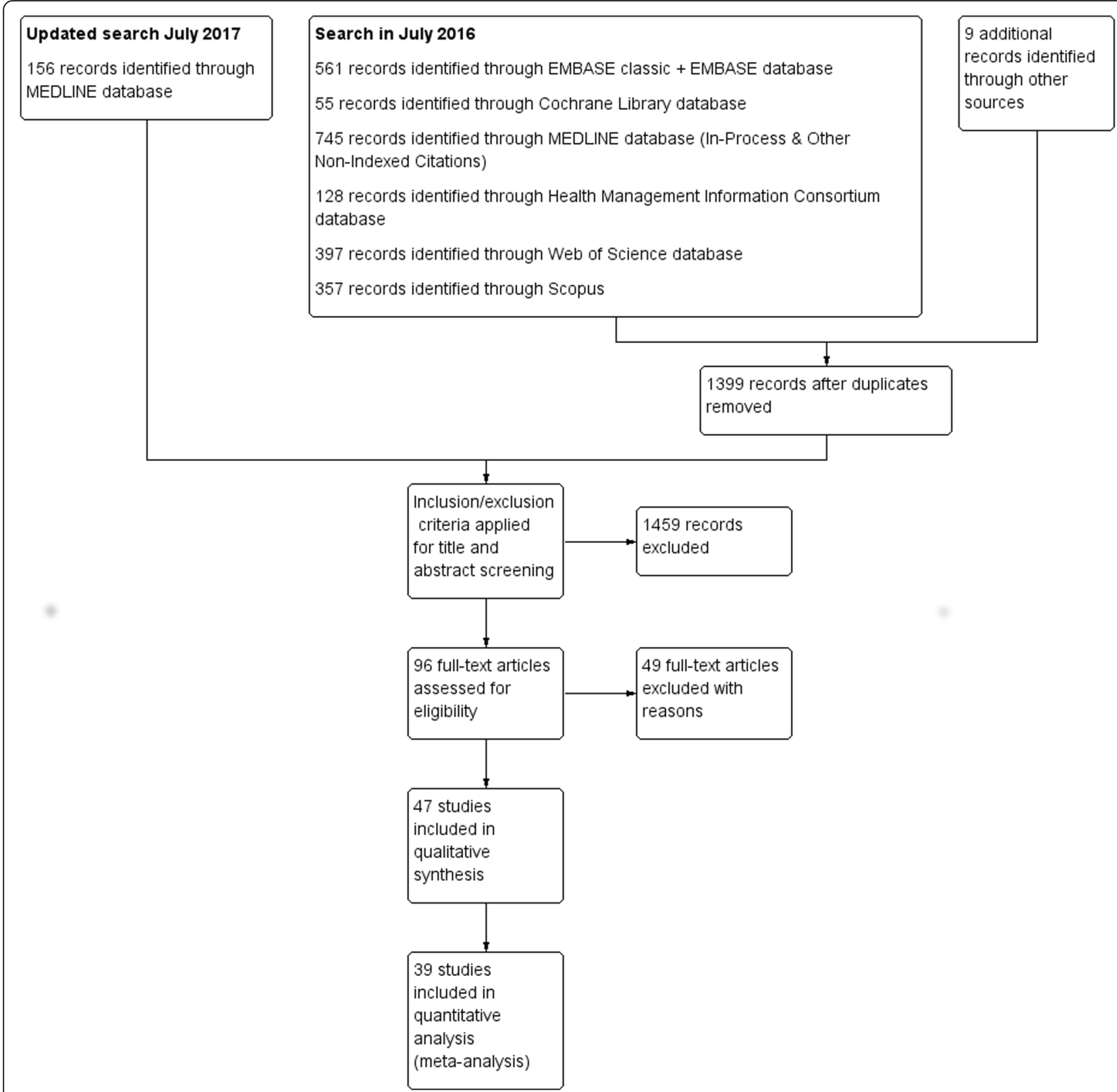

Fig. 1 Flow diagram of studies selected for meta-analysis

covered a range of diagnoses. The majority of studies (76\%) included data from more than one year. The majority of studies (62\%) were national (England, Scotland, Wales, Northern Ireland or some combination of these), and a further $20 \%$ were single-site studies. Other studies were either regional or a sample of sites from the UK.

\section{Patient groups - diagnoses}

A key difference in studies is whether they investigated all-cause outcomes or condition-specific outcomes. 14 studies focussed on all-cause admissions, although some of these analyse specific conditions within the papers.
Eight studies consider stroke admissions only. Other specific conditions studied included upper gastrointestinal bleeding and COPD.The availability of clinical registries or audits affects is also related to whether specific diseases were studied.

Adjustment of outcomes and inclusion of severity measures The majority analyses attempted to take into account potential confounders and severity at admission or attendance, but the approaches varied. We classified severity as being specific to the disease of focus, if applicable. We did not include proxies such as mode of arrival or referral, 
disease type or comorbidities as measures of severity. Fourteen studies included a measure of severity. One study considered all-cause emergency admissions, and the remaining studies were disease-specific (stroke:5; ICU:2; hip fracture:2; COPD:1; UGIB:1; and paediatric outcomes:1). Measures of severity varied between diseases. For example, both studies focussing on the outcomes of hip fracture patients used the American Society of Anaesthesiologists physical status classification. Both ICU studies used the APACHE II system, although one study used the combined score and one used individual components. The stroke studies used a variety of measures of severity including the National Institutes of Health Stroke Score, the modified Rankin scale, the worst level of consciousness in the previous $24 \mathrm{~h}$ and whether a palliative care decision was made in the first $24 \mathrm{~h}$.

In addition to studies that included a measure of severity, various studies claimed to use proxies for severity, including mode of arrival at hospital, arguing that arriving by ambulance was a proxy for more severe patients [20]. Several studies categorise patients based on the clinical risk associated with the primary diagnoses.

\section{Narrative analysis}

All abstract conclusions were read by two reviewers. We determined whether the emphasis of the conclusion was that there was no weekend effect, a weekend effect or no mention of the effect. Three studies did not mention the weekend effect as part of their conclusions. For two of these, day of the week was not part of the aim set out in the abstract. A third study did mention the higher weekend mortality in the abstract, but this was not part of a specific aim. For 24 of the studies the abstract concluded that outcomes for patients either undergoing surgery or admitted at the weekend were worse. The proportion of studies reporting a weekend effect was higher before the Secretary of State's statement (65\% compared with 37\%). 18 studies concluded that there was no effect, $31 \%$ of those published before and 53\% of those published after the controversial statement by the Secretary of State. Of the studies which reported no effect [5, 20-34] there was some evidence that the results of the statistical analysis indicated worse outcomes for patients admitted at weekends (two of the eight published before [21, 33] and six of the 10 published after [20, 24, 28, 31, 33, 35]). These included studies that tried different methods of adjustment, for example Wunsch et al. [22] who tried two forms of adjustment, one which resulted in a significant effect and which did not, and used the phrase "After appropriate adjustment". Anselmi et al. [20] also used different adjustment methods, and found that "Using conventional risk-adjustment methods, there appears to be a higher risk of mortality .....". When model of arrival was included in the adjustment approach there was no significant effect. One study aimed to mitigate any effect by using the phrase 'limited effect' [35].

\section{Quantitative analysis}

34 articles were included in the main meta-analysis, which contributed 50 separate analyses. These are summarised in Table 2. Meta-analysis on these studies showed that patients admitted at the weekend had a significantly higher mortality than those admitted during the week $(\mathrm{OR}=1.07$, 95\% CI: 1.03 to 1.12). These are summarised in Fig. 2. Five articles, reporting hazard ratios in 7 analyses, included in a separate meta-analysis, had similar findings $(\mathrm{HR}=1.09$, 95\% CI: 1.05 to 1.14 ), see Additional file 2.

\section{Subgroup analyses}

Table 3 shows the results of the sub-group analyses. There was no evidence that there was any association between publication date and weekend outcomes. Regardless of population size, there is evidence of a higher mortality rate for weekend admissions. However, the confidence interval for the studies with the smallest populations includes one, which suggests that when only small studies are analysed there is limited evidence to support the weekend effect. Studies based on clinical registry/audit data did not show that weekend patients had significantly worse outcomes. However, none of the studies with 100,000 patients or more were clinical registries/audits. The division between administrative and clinical data sets is often used a proxy for having clinical information. We also divided studies into those that included measures of severity and those that did not. We did not find an association between studies which included a measure of severity and higher mortality for weekend admissions.

\section{Discussion \\ Main findings}

We found evidence that when studies are combined there is evidence of a weekend effect, with patients admitted at the weekend having higher odds of mortality that was not explained by measures of severity included in the studies. However, there were high levels of heterogeneity in the meta-analysis, suggesting there may be some concerns about the generalisability of the result. We found considerable variation in the approaches taken, including the time period for mortality, the definition of weekend and the variables included as measures of severity, which all contribute to the high levels of heterogeneity and are likely to be a cause of some of the conflicting results and their interpretation.

We included 45 papers in the qualitative analysis. The majority of these were published in the last three years. Just over half of these studies (53\%) concluded that outcomes for patients either undergoing surgery or 


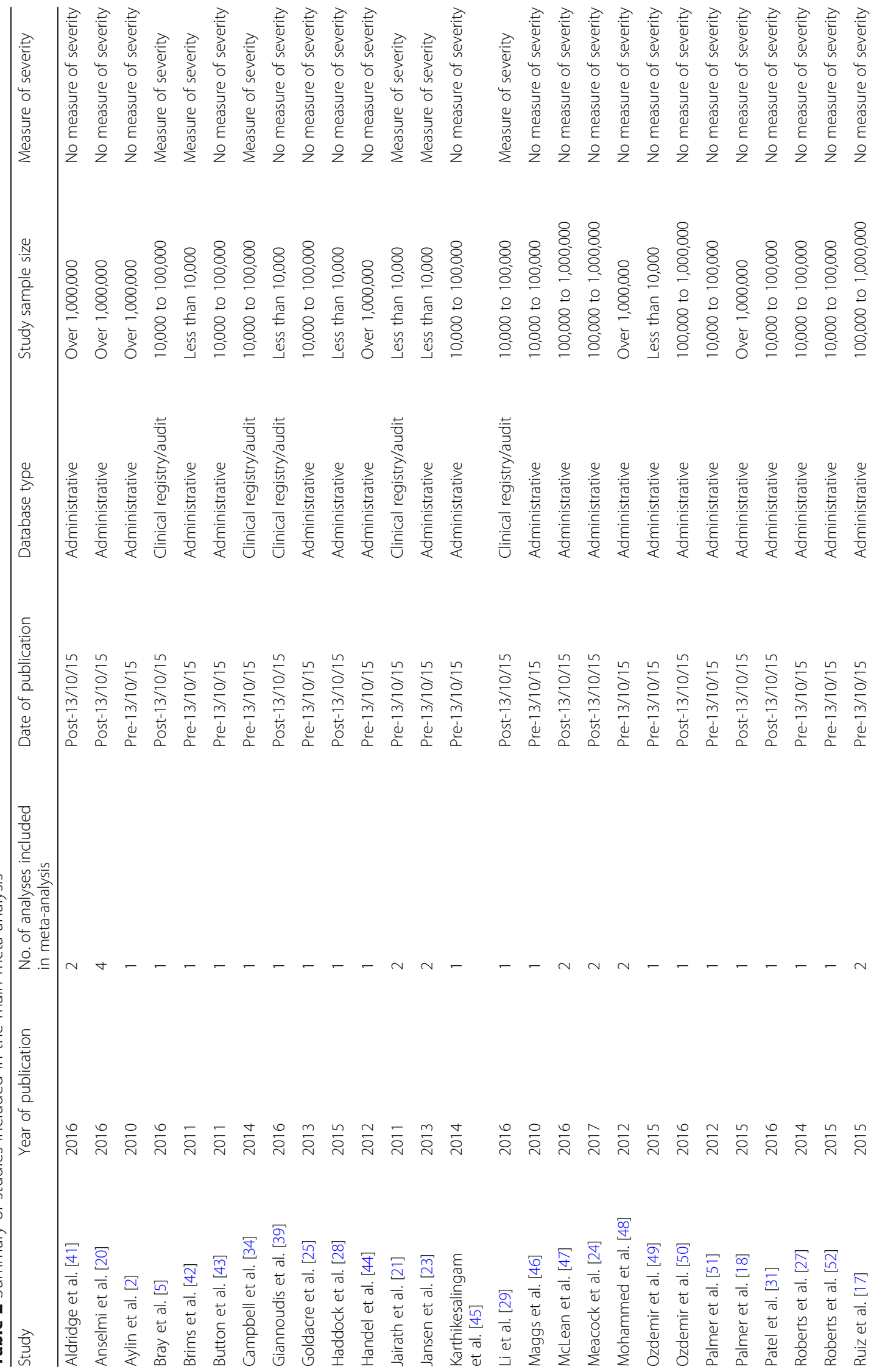




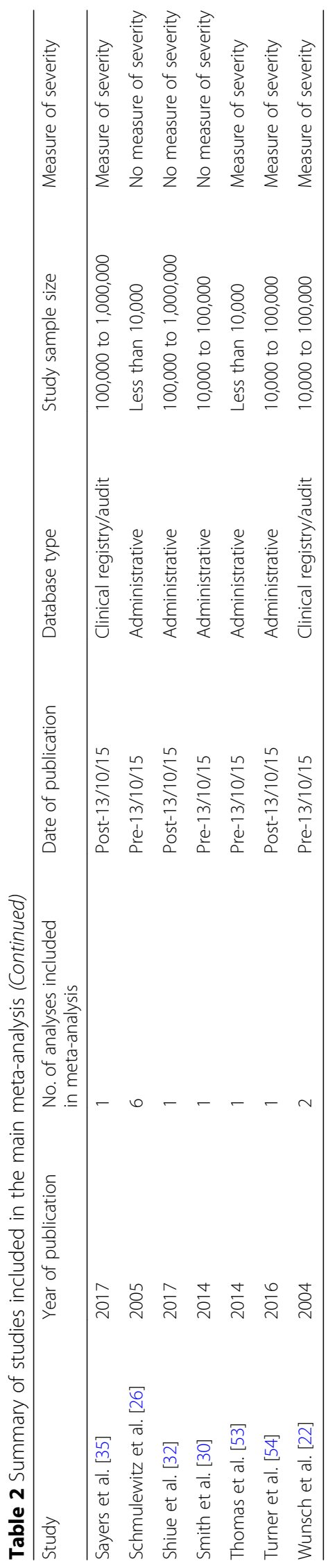




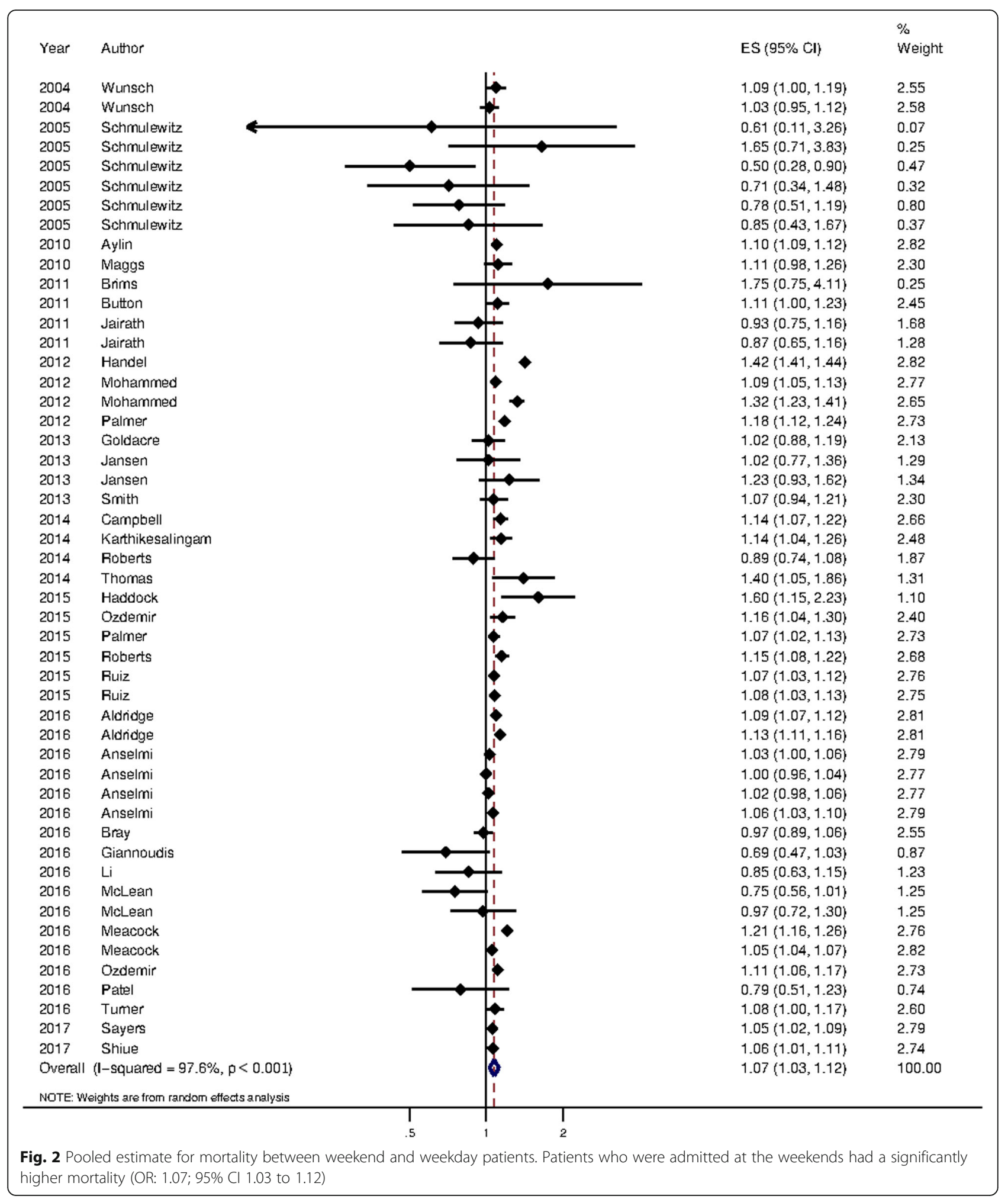

admitted at the weekend were worse. The proportion of papers that concluded that outcomes for weekend patients were worse decreased after the statement by the Secretary of State in October 2015. We included 34 papers in the meta-analysis which contributed 50 studies, 26 of which found evidence of a weekend effect. We found an overall effect of 1.07 [odds ratio (OR)] (95\% CI 1.03-1.12), suggesting that patients admitted at the 
Table 3 Sub-group analyses

\begin{tabular}{|c|c|c|c|c|}
\hline Subgroup & Number of analyses & OR $(95 \% \mathrm{Cl})$ & $p$-value & $1^{2}(\%)$ \\
\hline All Analyses ${ }^{a}$ & 50 & $1.07(1.03,1.12)$ & 0.002 & 97.6 \\
\hline \multicolumn{5}{|l|}{ Date of publication ${ }^{b}$} \\
\hline - Pre-October 13th $2015^{c}$ & 30 & $1.09(1.02,1.17)$ & 0.009 & $97.5 \%$ \\
\hline - Post-October 13th 2015 & 20 & $1.06(1.03,1.09)$ & $<0.001$ & $84.0 \%$ \\
\hline \multicolumn{5}{|l|}{ Study sample size } \\
\hline - Less than 10,000 & 15 & $1.03(0.89,1.18)$ & 0.72 & $57.9 \%$ \\
\hline • 10,000 to 100,000 & 15 & $1.08(1.04,1.13)$ & $<0.001$ & $57.1 \%$ \\
\hline - 100,000 to $1,000,000$ & 8 & $1.08(1.04,1.30)$ & 0.001 & $81.9 \%$ \\
\hline • Over $1,000,000$ & 12 & $1.11(1.02,1.21)$ & 0.015 & $99.4 \%$ \\
\hline \multicolumn{5}{|l|}{ Database type } \\
\hline - Administrative & 41 & $1.09(1.04,1.15)$ & $<0.001$ & $98.0 \%$ \\
\hline - Clinical registry/audit & 9 & $1.03(0.98,1.09)$ & 0.25 & $57.8 \%$ \\
\hline \multicolumn{5}{|l|}{ Measure of severity } \\
\hline - No measure of severity & 37 & $1.08(1.03,1.14)$ & 0.004 & $98.2 \%$ \\
\hline - Measure of severity & 13 & $1.06(1.02,1.10)$ & $<0.001$ & $43.5 \%$ \\
\hline
\end{tabular}

${ }^{\mathrm{a}} 50$ analyses from 34 published articles

${ }^{b}$ Date of publication was used rather than submission as date of submission was not available for all articles

'The 13th October 2015 was the date of the Minister Of Health's statement in the House of Commons about the weekend effect

weekend had higher odds of mortality that those admitted during the week. Sub-group analyses suggest that the weekend effect remained when measures of severity were included in the models, but that the weekend effect was not significant when clinical registry data was used.

\section{Strengths and weaknesses}

This study is the first review to focus on admissions to hospitals in the United Kingdom (UK). This is a strength in that hospitals across the UK are relatively homogenous and although patient demographics vary, the health system is comparable across regions of the UK. The main limitation of the study is the high heterogeneity, which means the estimate of the effect size from the meta-analysis may not be valid. The high heterogeneity was expected as the nature of the studies we included varied in terms of size, disease, time to outcome and other factors and is in line with other systematic reviews on the weekend effect [12]. Some of the sub-groups exhibited lower heterogeneity and the weekend effect remained significant, for example studies which included a measure of severity. The restriction of studies to those within the UK limits the generalisability of the findings to other countries but is important for local and national policy, and other studies have already established that the weekend effect is an international phenomenon. We consider the categorisation of papers into those that include a severity measure to be a key strength as a common explanation of the weekend effect is that more severe patients are admitted at the weekend (for example see [24]). Previous systematic reviews $[11,13]$ carried out sub-group analyses on different diagnostic categories, we were concerned that the small numbers of studies in the majority of categories would not add this area. Our investigation of the impact of a major political announcement on research publications is important. It has been shown that confirmation bias can affect how researchers interpret results [36] and unconscious bias can influence research evaluation [37]. However, we acknowledge that we have only completed an initial analysis, and there is the risk of our own bias influencing the interpretation of abstracts. There is also the risk of bias as two of the authors (D and B) of this paper are also authors of various research papers and commentaries on the weekend effect. We endeavoured to overcome this potential bias by involving researchers $(\mathrm{E}, \mathrm{C}$ and $\mathrm{A}$ ) who have not previously published on this topic and were new to much of the literature. We did not attempt to determine whether the outcomes were associated with quality of care or weekend staffing, and we cannot offer explanations as to the cause of the weekend effect.

This review has shown that hospital mortality does differ between weekends and weekdays in the UK, consistent with two recent reviews, both showing poorer outcomes for patients admitted at the weekend [11, 12]. Despite the increase in publications in recent years and the rise in discussion of the topic in the media, we did not find an association between the date of publication and the relative risk of mortality when we carried out a sub-group meta-analysis. However, our narrative analysis, which considered the overall conclusions drawn by the authors, showed evidence of change over time. The increasing need for health services research to have 
impact has led to researchers increasingly choosing to study topics with policy leverage and 'present them in a manner that policy makers think about these issues' [38]. These pressures may influence not only topics for research, but also interpretation and publication. Sub-group analyses showed that regardless of sample size, there was a higher risk of worse outcomes for patients admitted at the weekend, but that this was not significant for smaller sample sizes. This may be due to a lack of power to detect significant differences in smaller samples, or that smaller studies may use different data sources or come from sites with different case-mix or with different weekend care.

We did find that the data source was associated with the weekend effect, with a non-significant effect for studies based on clinical data. However, when we divided studies based on the inclusion of a severity measure the weekend effect remained in both groups. We found that the use of clinical audit data did not necessarily mean that measures of severity were included in the analysis [39] and that measures of severity inevitably varied. In a systematic review of the effect of weekend admission on outcomes for patients with upper gastrointestinal bleeding, variceal bleeding was not associated with weekend admission, but non-variceal bleeding was, suggesting that a more sophisticated approach than a 'severity measure' may be important and may be disease-specific [40].

\section{Conclusion}

In this systematic review, we found evidence of a weekend effect. However, the high levels of heterogeneity in study design, including outcomes and the inclusion of confounder, mean it is not possible to quantify the effect accurately. We suggest that individual hospital managers examine their own performance carefully and if poorer outcomes are found for weekend admissions possible reasons are examined. We found a weekend effect even after accounting for severity of disease, further work is required to examine other potential explanations for the "weekend effect" such as staffing levels and other organisational factors.

\section{Additional files}

Additional file 1: Free Text and MeSH Heading terms used in Literature Search. Baseline characteristics of all studies. Assessment of bias using CASP questions. (DOCX $159 \mathrm{~kb}$ )

Additional file 2: Figure 1. Flow diagram of studies selected for metaanalysis. Figure 2. Additional meta-analysis of studies reporting hazard ratios. Table 1 . Summary of studies in additional meta-analysis (those reporting hazard ratios). (DOCX $172 \mathrm{~kb}$ )

\section{Abbreviations}

CASP: Critical Appraisal Skills Programme; Cl: Confidence interval;

COPD: Chronic obstructive pulmonary disorder; $I^{2}$ : Measure of heterogeneity;
ICU: Intensive care unit; NHS: National Health Service; OR: Odds ratio; UGIB: Upper gastro-intestinal bleeding; UK: United Kingdom

\section{Funding}

The views expressed in this publication are those of the authors. The Dr. Foster Unit is an academic unit in the Department of Primary Care and Public Health, within the School of Public Health, Imperial College London. The unit receives research funding from the National Institute of Health Research and Dr. Foster Intelligence, an independent health service research organisation (a wholly owned subsidiary of Telstra). The Dr. Foster Unit at Imperial is affiliated with the National Institute of Health Research (NIHR) Imperial Patient Safety Translational Research Centre. The NIHR Imperial Patient Safety Translational Centre is a partnership between the Imperial College Healthcare NHS Trust and Imperial College London. The Department of Primary Care \& Public Health at Imperial College London is grateful for support from the NW London NIHR Collaboration for Leadership in Applied Health Research \& Care (CLAHRC) and the Imperial NIHR Biomedical Research Centre.

\section{Availability of data and materials}

The datasets used and/or analysed during the current study are available from the corresponding author on reasonable request.

\section{Authors' contributions}

$\mathrm{ML}$ and PA contributed to the original protocol. ML, EC and PA carried out the search and review of literature. EC carried out the analysis. All authors contributed to early drafts of the paper, $\mathrm{KH}$ wrote later drafts, bringing together the work completed by other contributors. PA, KH, AB and EC contributed to the final version of the paper. All authors have read and approved the manuscript.

\section{Ethics approval and consent to participate}

Not applicable. No humans or animals were used in this study, which is based completely on published material.

\section{Consent for publication}

Not applicable. No humans or animals were used in this study, which is based completely on published material.

\section{Competing interests}

All authors have completed the ICMJE uniform disclosure form at www.icmje.org/coi_disclosure.pdf (available on request from the corresponding author) and declare: PA reports grants from Dr. Foster Intelligence, during the conduct of the study; no financial relationships with any organisation that might have interest in the submitted work in the previous three years; no other relationships or activities that could appear to have influenced the submitted work.

\section{Publisher's Note}

Springer Nature remains neutral with regard to jurisdictional claims in published maps and institutional affiliations.

\section{Author details}

'Department of Primary Care and Public Health, Dr Foster Unit at Imperial College, 3 Dorset Rise, London EC4Y 8EN, UK. ${ }^{2}$ Department of Family Medicine and Primary Healthcare, Hospital Authority, Hong Kong, Hong Kong.

Received: 16 July 2018 Accepted: 5 November 2018 Published online: 20 November 2018

References

1. MacFarlane A. Variations in number of births and perinatal mortality by day of week in England and Wales. Br Med J. 1978;2(6153):1670-3.

2. Aylin P, Yunus A, Bottle A, Majeed A, Bell D. Weekend mortality for emergency admissions. A large, multicentre study. Qual Saf Health Care. 2010;19(3):213-7.

3. Bell D, Lambourne A, Percival F, et al. Consultant input in acute medical admissions and patient outcomes in hospitals in England: a multivariate analysis. PLoS One. 2013;8(4):e61476.

4. Metcalfe D, Castillo-Angeles M, Rios-Diaz AJ, et al. Is there a "weekend effect" in emergency general surgery? J Surg Res. 2018;222:219-24. 
5. Bray BD, Cloud GC, James MA, et al. Weekly variation in health-care quality by day and time of admission: a nationwide, registry-based, prospective cohort study of acute stroke care. Lancet. 2016;388(10040):170-7.

6. Siddique $H$. Weekend-born babies slightly more likely to die in their first week. London: The Guardian; 2015. Available from: www.theguardian.com/ society/2015/nov/24/weekend-born-babies-slightly-more-likely-to-die-intheir-first-week. Accessed on 19 Apr 2018.

7. Hansard HC Deb (13 October 2015) Oral Answers to Questions Health Col 147. Available at: https://publications.parliament.uk/pa/ cm201516/cmhansrd/cm151013/debtext/151013-0001.htm. Accessed 14 Nov 2011.

8. Furnivall $D$, Bottle A, Aylin P. Retrospective analysis of the national impact of industrial action by English junior doctors in 2016. BMJ Open. 2018;8: e019319. https://doi.org/10.1136/bmjopen-2017-019319.

9. Sorita A, Ahmed A, Starr SR, et al. Off-hour presentation and outcomes in patients with acute ischemic stroke: a systematic review and meta-analysis. Eur J Intern Med. 2014;25(4):394-400.

10. Sorita A, Ahmed A, Starr SR, et al. Off-hour presentation and outcomes in patients with acute myocardial infarction: systematic review and metaanalysis. BMJ. 2014;348:f7393.

11. Zhou Y, Li W, Herath C, et al. Off-hour admission and mortality risk for 28 specific diseases: a systematic review and meta-analysis of 251 cohorts. J Am Heart Assoc. 2016;5(3):e003102.

12. Pauls LA, Johnson-Paben R, McGready J, et al. The weekend effect in hospitalized patients: a meta-analysis. J Hosp Med. 2017;12(9):760-6.

13. Hoshijima H, Takeuchi R, Mihara T, et al. Weekend versus weekday admission and short-term mortality. Medicine. 2017;96(17):e6685. https://doi. org/10.1097/MD.0000000000006685.

14. McShane P, Draper ES, McKinney PA, et al. Effects of out-of-hours and winter admissions and number of patients per unit on mortality in pediatric intensive care. J Pediatr. 2013;163(4):1039-44 e5.

15. Mohammed MA, Faisa LM, Richardson D, et al. RETRACTED: adjusting for illness severity shows there is no difference in patient mortality at weekends or weekdays for emergency medical admissions. QJM. 2017;110(7):e1-8.

16. Deshmukh $H$, Hinkley $M$, Dulhanty $L$, et al. Effect of weekend admission on in-hospital mortality and functional outcomes for patients with acute subarachnoid haemorrhage (SAH). Acta Neurochir. 2016;158(5):829-35

17. Ruiz M, Bottle A, Aylin PP. The global comparators project: international comparison of 30-day in-hospital mortality by day of the week. BMJ Qual Saf. 2015;24(8):492-504

18. Palmer WL, Bottle A, Davie C, Vincent CA, Aylin P. Dying for the weekend: a retrospective cohort study on the association between day of hospital presentation and the quality and safety of stroke care. Arch Neurol. 2012; 69(10):1296-302.

19. Freemantle N, Richardson M, Wood J, et al. Weekend hospitalization and additional risk of death: an analysis of inpatient data. J R Soc Med. 2012; 105(2):74-84.

20. Anselmi L, Meacock R, Kristensen SR, et al. Arrival by ambulance explains variation in mortality by time of admission: retrospective study of admissions to hospital following emergency department attendance in England. BMJ Qual Saf. 2017;26(8):613-21.

21. Jairath $\mathrm{V}$, Kahan $\mathrm{BC}$, Logan RF, et al. Mortality from acute upper gastrointestinal bleeding in the United Kingdom: does it display a "weekend effect"? Am J Gastroenterol. 2011;106(9):1621-8.

22. Wunsch H, Mapstone J, Brady T, et al. Hospital mortality associated with day and time of admission to intensive care units. Intensive Care Med. 2004; 30(5):895-901.

23. Jansen JO, MacLennan GS, Cuthbertson BH. Effect of day and time of admission on mortality in an intensive care unit. J Intensive Care Soc. 2013; 14(4):294-8.

24. Meacock R, Anselmi L, Kristensen SR, et al. Higher mortality rates amongst emergency patients admitted to hospital at weekends reflect a lower probability of admission. J Health Serv Res Policy. 2017; 22(1):12-9.

25. Goldacre MJ, Maisonneuve JJ. Mortality from meningococcal disease by day of the week: English national linked database study. J Public Health. 2013; 35(3):413-21.

26. Schmulewitz $L$, Proudfoot A, Bell D. The impact of weekends on outcome for emergency patients. Clin Med. 2005;5(6):621-5.
27. Roberts SE, Thorne K, Evans PA, et al. Mortality following acute pancreatitis: social deprivation, hospital size and time of admission: record linkage study. BMC Gastroenterol. 2014;14:153.

28. Haddock R, Deighan C, Thomson PC. In-patient hospital mortality patterns by day of the week: an analysis of admissions to a regional renal unit. Scott Med J. 2016;61(4):179-84.

29. Li L, Rothwell PM, Oxford Vascular S. Biases in detection of apparent "weekend effect" on outcome with administrative coding data: population based study of stroke. BMJ. 2016;353:i2648.

30. Smith S, Allan A, Greenlaw N, et al. Emergency medical admissions, deaths at weekends and the public holiday effect. Cohort study. Emerg Med J. 2014;31(1):30-4.

31. Patel R, Chesney E, Cullen AE, et al. Clinical outcomes and mortality associated with weekend admission to psychiatric hospital. Br J Psychiatry. 2016:209(1):29-34

32. Shive I, McMeekin P, Price C. Retrospective observational study of emergency admission, readmission and the 'weekend effect'. BMJ Open. 2017;7(3):e012493.

33. Walker AS, Mason A, Quan TP, et al. Mortality risks associated with emergency admissions during weekends and public holidays: an analysis of electronic health records. Lancet. 2017:390(10089):62-72.

34. Campbell JT, Bray BD, Hoffman AM, et al. The effect of out of hours presentation with acute stroke on processes of care and outcomes: analysis of data from the Stroke Improvement National Audit Programme (SINAP). PLoS One. 2014;9(2):e87946.

35. Sayers A, Whitehouse MR, Berstock JR, et al. The association between the day of the week of milestones in the care pathway of patients with hip fracture and 30-day mortality: findings from a prospective national registry - The National Hip Fracture Database of England and Wales. BMC Med. 2017;15(1):62.

36. Kaptchuk TJ. Effect of interpretive bias on research evidence. BMJ. 2003; 326(7404):1453-5

37. Harris M, Macinko J, Jimenez G, et al. Measuring the bias against low-income country research: an implicit association test. Glob Health. 2017;13(1):80.

38. Blendon RJ, Steelfisher GK. Commentary: understanding the underlying politics of health care policy decision making. Health Serv Res. 2009; 44(4):1137-43.

39. Giannoudis V, Panteli M, Giannoudis PV. Management of polytrauma patients in the UK: is there a 'weekend effect'? Injury. 2016:47(11):2385-90.

40. Shih PC, Liu SJ, Li ST, et al. Weekend effect in upper gastrointestinal bleeding: a systematic review and meta-analysis. PeerJ. 2018:6:e4248. https://doi.org/10.7717/peerj.4248.

41. Aldridge C, Bion J, Boyal A, Chen YF, Clancy M, Evans T, et al. Weekend specialist intensity and admission mortality in acute hospital trusts in England: a cross-sectional study. Lancet. 2016;388(10040):178-86.

42. Brims FJ, Asiimwe A, Andrews NP, Prytherch D, Higgins BR, Kilburn S, et al. Weekend admission and mortality from acute exacerbations of chronic obstructive pulmonary disease in winter. Clin Med (Lond). 2011;11(4):334-9.

43. Button LA, Roberts SE, Evans PA, Goldacre MJ, Akbari A, Dsilva R, et al. Hospitalized incidence and case fatality for upper gastrointestinal bleeding from 1999 to 2007: a record linkage study. Aliment Pharmacol Ther. 2011; 33(1):64-76

44. Handel AE, Patel SV, Skingsley A, Bramley K, Sobieski R, Ramagopalan SV. Weekend admissions as an independent predictor of mortality: an analysis of Scottish hospital admissions. BMJ Open. 2012;2:e001789. https://doi.org/ 10.1136/bmjopen-2012-001789.

45. Karthikesalingam A, Holt PJ, Vidal-Diez A, Ozdemir BA, Poloniecki JD, Hinchliffe RJ, et al. Mortality from ruptured abdominal aortic aneurysms: clinical lessons from a comparison of outcomes in England and the USA. Lancet. 2014:383(9921):963-9.

46. Maggs F, Mallet M. Mortality in out-of-hours emergency medical admissions--more than just a weekend effect. J R Coll Physicians Edinb. 2010;40(2):115-8.

47. McLean RC, McCallum IJ, Dixon S, O'Loughlin P. A 15-year retrospective analysis of the epidemiology and outcomes for elderly emergency general surgical admissions in the North East of England: a case for multidisciplinary geriatric input. Int J Surg. 2016;28:13-21

48. Mohammed MA, Sidhu KS, Rudge G, Stevens AJ. Weekend admission to hospital has a higher risk of death in the elective setting than in the emergency setting: a retrospective database study of national health service hospitals in England. BMC Health Serv Res. 2012;12:87. 
49. Ozdemir BA, Karthikesalingam A, Sinha S, Poloniecki JD, Vidal-Diez A, Hinchliffe RJ, et al. Association of hospital structures with mortality from ruptured abdominal aortic aneurysm. Br J Surg. 2015;102(5):516-24.

50. Ozdemir BA, Sinha S, Karthikesalingam A, Poloniecki JD, Pearse RM, Grocott MP, et al. Mortality of emergency general surgical patients and associations with hospital structures and processes. Br J Anaesth. 2016;116(1):54-62. https://doi.org/10.1093/bja/aev372.

51. Palmer WL, Bottle A, Aylin P. Association between day of delivery and obstetric outcomes: observational study. BMJ. 2015;351:h5774.

52. Roberts SE, Thorne K, Akbari A, Samuel DG, Williams JG. Mortality following stroke, the weekend effect and related factors: record linkage study. PLoS One. 2015;10(6):e0131836.

53. Thomas CJ, Smith RP, Uzoigwe CE, Braybrooke JR. The weekend effect: short-term mortality following admission with a hip fracture. Bone Joint J. 2014;96-B(3):373-8.

54. Turner M, Barber M, Dodds H, Dennis M, Langhorne P, Macleod MJ, et al. Stroke patients admitted within normal working hours are more likely to achieve process standards and to have better outcomes. J Neurol Neurosurg Psychiatry. 2016;87(2):138-43

Ready to submit your research? Choose BMC and benefit from:

- fast, convenient online submission

- thorough peer review by experienced researchers in your field

- rapid publication on acceptance

- support for research data, including large and complex data types

- gold Open Access which fosters wider collaboration and increased citations

- maximum visibility for your research: over $100 \mathrm{M}$ website views per year

At $\mathrm{BMC}$, research is always in progress.

Learn more biomedcentral.com/submissions 